\title{
Book Review: Health Economics and Policy Challenges in Global Emerging Markets
}

\author{
Milena Jurisevic* \\ Faculty of Medical Sciences, Department of Pharmacy, University of Kragujevac, Kragujevac, Serbia
}

Keywords: emerging markets, health economics, global health, medicine, health policy, BRICS, next eleven

\author{
A book review on \\ Health Economics and Policy Challenges in Global Emerging Markets
}

by Jakovljevic M, editor. New York: Nova Science Publishers, Inc. (2016). ISBN 978-1-63484-720-9

\section{OPEN ACCESS}

Edited by:

Rumen Stefanov,

Plovdiv Medical University,

Bulgaria

Reviewed by:

Ralitsa Dimitrova Raycheva, Plovdiv Medical University, Bulgaria

Tomofumi Anegawa, Keio University, Japan

${ }^{*}$ Correspondence: Milena Jurisevic milenajm@yahoo.com

Specialty section:

This article was submitted to Health Economics,

a section of the journal

Frontiers in Public Health

Received: 21 July 2017 Accepted: 28 August 2017 Published: 12 September 2017

Citation:

Jurisevic M (2017) Book Review: Health Economics and Policy Challenges in Global

Emerging Markets.

Front. Public Health 5:244. doi: 10.3389/fpubh.2017.00244
The book entitled "Health Economics and Policy Challenges in Global Emerging Markets," edited by Prof. Mihajlo (Michael) Jakovljevic MD, PhD (1) describes some of the key global health challenges at the beginning of the twenty-first century. Notable health economists in the field based in USA, Japan, China, and European countries (Germany, the Netherlands, Switzerland, Ireland, Serbia, Bulgaria, Poland, and Albania) affiliated to the some of the top ranked universities contributed with their diverse expert profiles in health economics, clinical medicine, public health, and population aging. The focus of the book is on the leading emerging countries and mature freemarket economies that face with the similar challenges including BRICS nations (Brazil, Russia, India, China, and South Africa) and N-11 nations (Bangladesh, Egypt, Indonesia, Iran, South Korea, Mexico, Nigeria, Pakistan, the Philippines, Turkey, and Vietnam), North American region, Far East Asia, Western, and Eastern Europe. Regional health-care issues in these countries related to the population aging $(2-4)$, health expenditures $(5-7)$, health technology assessment $(8,9)$, insurance coverage (10-12), costs of pharmaceutical development $(13,14)$, economics of prosperity diseases (15-18), public health legislation (19), and caregiver assessment (20) are processed in seven chapters of the book.

The first chapter describes the trends in population aging and health expenditures in emerging markets of BRICS and N-11 nations thus complementing and expanding previous research in this field (21-24). The second chapter tries to answer the question "What can emerging markets learn from a public long-term care insurance system from a mature country?" by trying to find who benefits the most among different age cohorts by the change in policy using the pooled data of the National Survey on Life Insurance in Japan. Use of multi-criteria decision analysis (MCDA) in health technology assessment is described in the third chapter, with a special emphasis on international experience and practical lessons from the real-world MCDA models. Bulgarian experience in incorporation of MCDA into health technology assessment, along with the description of the weaknesses of this process, substantially adds to the current literature on this issue (25-27). Willingness-to-pay for a new pharmaceutical is a focus of the fourth chapter of the book through an example of the study, which sought to provide evidence for making a decision on whether a new pharmaceutical for insulin therapy should be included in the benefit list of social health insurance in Germany. The fifth chapter discusses the role of the health economics in psychiatry and non-epileptic attack disorder (NEAD) with its uniqueness characterized by crossing the boundaries of emergency medicine, neurology, and psychiatry. Study described in this chapter more specifically dealt with calculation of an estimate of the prevalence and incidence 
of NEAD along with its economic burden in Ireland. Attempt to define the key challenges and needs in terms of legislation of the public health system in Poland is presented in Chapter 6 based on the analysis of the collected opinions and positions of Polish public health system stakeholders. The final chapter in the book, Chapter 7, aimed to provide an example of how to quantify family caregiver burden in traditional East-Asian societies.

As can be seen from this brief outline of the book, combined efforts of the broad spectrum of the health economists have greatly contributed to the quality and comprehensiveness of the book. Various aspects of the current health economics and health policy challenges in emerging markets were covered and strategies to cope with these issues were analyzed. Intended themes

\section{REFERENCES}

1. Jakovljevic M, editor. Health Economics and Policy Challenges in Global Emerging Markets. New York: Nova Science Publishers, Inc. (2016).

2. Jakovljevic M. The aging of Europe. The unexplored potential. Farmeconomia Health Econ Ther Pathw (2015) 16:89. doi:10.7175/fe.v16i4.1220

3. Jakovljevic MM, Laaser U. Population aging from 1950 to 2010 in seventeen transitional countries in the wider region of South Eastern Europe. SEEJPH (2015) 3. doi:10.12908/SEEJPH-2014-42

4. Ogura S, Jakovljevic M. Health financing constrained by population aging an opportunity to learn from Japanese experience. Ser J Exp Clin Res (2014) 15:175-81. doi:10.2478/SJECR-2014-0022

5. Getzen TE. Population aging and the growth of health expenditures. J Gerontol (1992) 47:S98-104. doi:10.1093/geronj/47.3.S98

6. Jakovljevic MB, Vukovic M, Fontanesi J. Life expectancy and health expenditure evolution in Eastern Europe-DiD and DEA analysis. Expert Rev Pharmacoecon Outcomes Res (2016) 16:537-46. doi:10.1586/14737167.2016. 1125293

7. Rancic N, Kovacevic A, Dragojevic-Simic V. Long-term health expenditure changes in selected Balkan countries. Front Public Health (2015) 3:152. doi:10.3389/fpubh.2015.00152

8. Dankó D, Petrova G. Health technology assessment in the Balkans: opportunities for a balanced drug assessment system. Biotechnol Biotechnol Equip (2014) 28:1181-9. doi:10.1080/13102818.2014.978636

9. Jakovljevic MB. Resource allocation strategies in Southeastern European health policy. Eur J Health Econ (2013) 14:153-9. doi:10.1007/s10198-0120439-y

10. Wang Q, Zhang D, Hou Z. Insurance coverage and socioeconomic differences in patient choice between private and public health care providers in China. Soc Sci Med (2016) 170:124-32. doi:10.1016/j.socscimed.2016. 10.016

11. Lagomarsino G, Garabrant A, Adyas A, Muga R, Otoo N. Moving towards universal health coverage: health insurance reforms in nine developing countries in Africa and Asia. Lancet (2012) 380:933-43. doi:10.1016/S01406736(12)61147-7

12. Jia L, Yuan B, Huang F, Lu Y, Garner P, Meng Q. Strategies for expanding health insurance coverage in vulnerable populations. Cochrane Database Syst Rev (2014) 11:1-78. doi:10.1002/14651858.CD008194.pub3

13. DiMasi JA, Grabowski HG, Hansen RW. Innovation in the pharmaceutical industry: new estimates of R\&D costs. J Health Econ (2016) 47:20-33. doi:10.1016/j.jhealeco.2016.01.012

14. Karampli E, Souliotis K, Polyzos N, Kyriopoulos J, Chatzaki E. Pharmaceutical innovation: impact on expenditure and outcomes and subsequent challenges for pharmaceutical policy, with a special reference to Greece. Hippokratia (2014) 18:100-6.

15. Kovacevic A, Dragojevic-Simic V, Tarabar D, Rancic N, Jacimovic N, Katic J, et al. Five-year survival and costs of care in metastatic colorectal cancer: conventional versus monoclonal antibody-based treatment protocols. Expert Rev Anticancer Ther (2015) 15:963-70. doi:10.1586/14737140.2015. 1059280 are presented in an organized and progressive manner, and each chapter contains an abstract and a thorough list of references. Overall, Editor and contributors have made a remarkable effort in assembling this book, and the readers will certainly benefit from the different perspectives presented in the book. I would like to highly recommend it to the broader target auditorium of policy makers, health-care professionals, and lay audience regardless whether their primary career background is dominantly academic, medical care, or industry based.

\section{AUTHOR CONTRIBUTIONS}

MJ is responsible for the design, writing the article, critical revision, and final approval of the manuscript.

16. Jakovljevic M, Varjacic M, Jankovic SM. Cost-effectiveness of ritodrine and fenoterol for treatment of preterm labor in a low-middle-income country: a case study. Value Health (2008) 11:149-53. doi:10.1111/j.15244733.2007.00222.x

17. Cupurdija V, Lazic Z, Petrovic M, Mojsilovic S, Cekerevac I, Rancic N, et al. Community-acquired pneumonia: economics of inpatient medical care vis-à-vis clinical severity. J Bras Pneumol (2015) 41:48-57. doi:10.1590/ S1806-37132015000100007

18. Jakovljevic M, Tetsuji Y, Ching C, Stevanovic D, Jovanovic M, Nikic-Djuricic K, et al. Cost-effectiveness of depressive episode pharmacological treatment. Hosp Pharmacol Int Multidiscip J (2015) 2:235-45. doi:10.5937/ hpimj1501235J

19. Meier BM, Tureski K, Bockh E, Carr D, Ayala A, Roberts A, et al. Examining national public health law to realize the global health security agenda. Med Law Rev (2017) 25:240-69. doi:10.1093/medlaw/fwx020

20. Adelman RD, Tmanova LL, Delgado D, Dion S, Lachs MS. Caregiver burden: a clinical review. JAMA (2014) 311:1052. doi:10.1001/jama.2014.304

21. Jakovljevic M, Potapchik E, Popovich L, Barik D, Getzen TE. Evolving health expenditure landscape of the BRICS nations and projections to 2025. Health Econ (2017) 26:844-52. doi:10.1002/hec.3406

22. Jakovljevic MM. Comparison of historical medical spending patterns among the BRICS and G7. J Med Econ (2016) 19:70-6. doi:10.3111/13696998.2015. 1093493

23. Jakovljevic MB, Milovanovic O. Growing burden of non-communicable diseases in the emerging health markets: the case of BRICS. Front Public Health (2015) 3:65. doi:10.3389/fpubh.2015.00065

24. Rancic N, Jakovljevic MM. Long term health spending alongside population aging in N-11 emerging nations. East Eur Bus Econ J (2016) 2:2-26.

25. Diaby V, Campbell K, Goeree R. Multi-criteria decision analysis (MCDA) in health care: a bibliometric analysis. Oper Res Health Care (2013) 2:20-4. doi:10.1016/j.orhc.2013.03.001

26. Marsh K, Lanitis T, Neasham D, Orfanos P, Caro J. Assessing the value of healthcare interventions using multi-criteria decision analysis: a review of the literature. Pharmacoeconomics (2014) 32:345-65. doi:10.1007/s40273014-0135-0

27. Iskrov G, Miteva-Katrandzhieva T, Stefanov R. Multi-criteria decision analysis for assessment and appraisal of orphan drugs. Front Public Health (2016) 4:214. doi:10.3389/fpubh.2016.00214

Conflict of Interest Statement: The author declares that the research was conducted in the absence of any commercial or financial relationships that could be construed as a potential conflict of interest.

The reviewer RDR and handling Editor declared their shared affiliation.

Copyright (c) 2017 Jurisevic. This is an open-access article distributed under the terms of the Creative Commons Attribution License (CC BY). The use, distribution or reproduction in other forums is permitted, provided the original author(s) or licensor are credited and that the original publication in this journal is cited, in accordance with accepted academic practice. No use, distribution or reproduction is permitted which does not comply with these terms. 